\title{
Laparoscopic Reversal of Tubal Ligation - A Minimally Invasive Option for Restoring Natural Fertility
}

\author{
S Yeo*, KH Chua and HH Tan \\ Singhealth, KK Women's and Children's Hospital, Singapore
}

Submission: January 16, 2019; Published: March 05, 2019

*Corresponding author: Samantha Yeo, Singhealth, KK Women's and Children's Hospital, Singapore

\section{Background}

Tubal sterilization is a common form of contraception which can be associated with regret and requests to restore fertility. Options for such patients include surgical reversal and in vitro fertilization (IVF). The gold standard for surgical reversal previously was laparotomy and microsurgery, however recent advances in laparoscopy have allowed minimally invasive surgery to be offered in selected patients with good outcomes.

\section{Case Description}
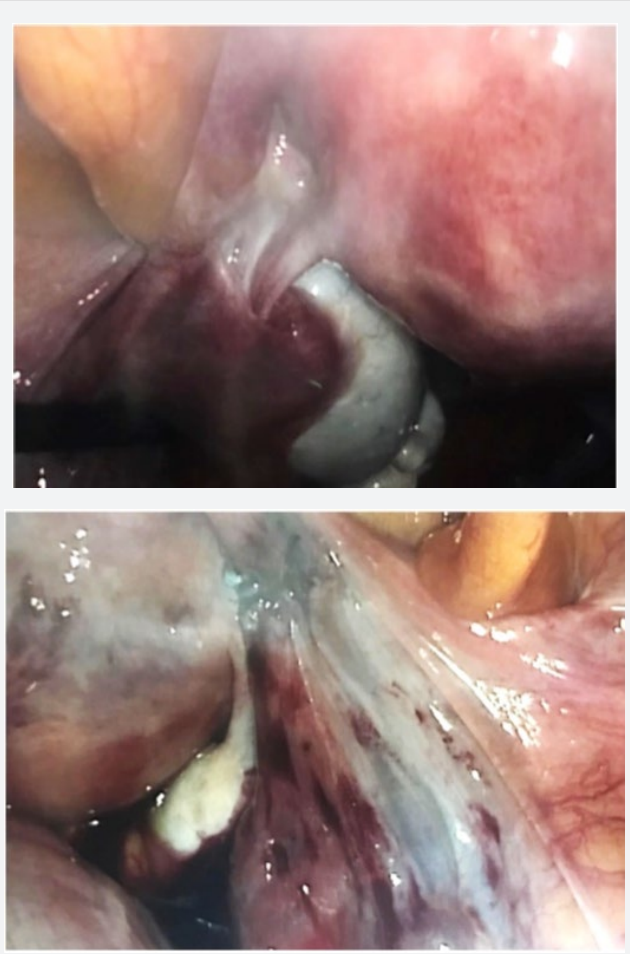

Figure 1: Prior to reanastomosis, bilateral fallopian tubes are surveyed for the length of remaining tube, calibre and presence of adhesions before proceeding with restorative surgery.

We present the case of 34-year-old multiparous woman who underwent reversal of tubal ligation and subsequently delivered a livebirth from a spontaneous conception. Our patient was a
34 year-old woman who was recently remarried and trying to conceive. Her obstetric history included four term normal vaginal deliveries from her previous partner, and two early miscarriages. After her last delivery four years ago, she underwent postpartum sterilization. This was performed with tubal occlusion using non absorbable titanium and silicon rubber clips (Filschie® clips) via a minilaparotomy (Figures 1) [1].

A secondary subfertility evaluation revealed good ovarian reserve and ovulatory cycles, with satisfactory semen parameters. Counseling was directed towards the options of reversal of tubal ligation and IVF. After understanding the various success and complication rates, she requested surgical reversal of tubal ligation as she was keen on spontaneous conception (Figure 2).

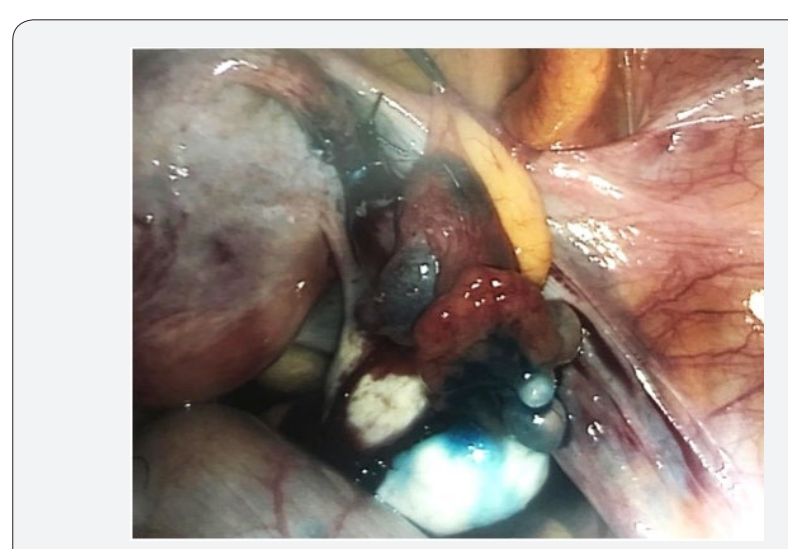

Figure 2: Methylene blue is used to identify the lumen of the proximal tube prior to reanastomosis.

She underwent laparoscopic reversal of tubal ligation and tubal re-anastomosis under general anaesthesia. Routine laparoscopic Veress entry was achieved and the status of her tubes was evaluated. Both Filschie® clips were removed with careful dissection. Methylene blue was use to identify the proximal and distal tubal lumens via hydrotubation and tubal cannulation.

Bilateral tubal reanastomosis was performed with microsurgical equipment via $3 \mathrm{~mm}$ laparoscopic ports. Vasopressin was infiltrated into the mesosalpinx and precise electrocoagulation 
was used to aid haemostasis. Two Polyproprylene $₫$ sutures were placed at the muscularis layers of both ends of each tube, at the 6 and 12 o'clock positions, and apposition of the proximal and distal lumens was achieved in a tension free fashion. Tubal patency was confirmed intra-operatively via hydrotubation (Figure 3) [2].
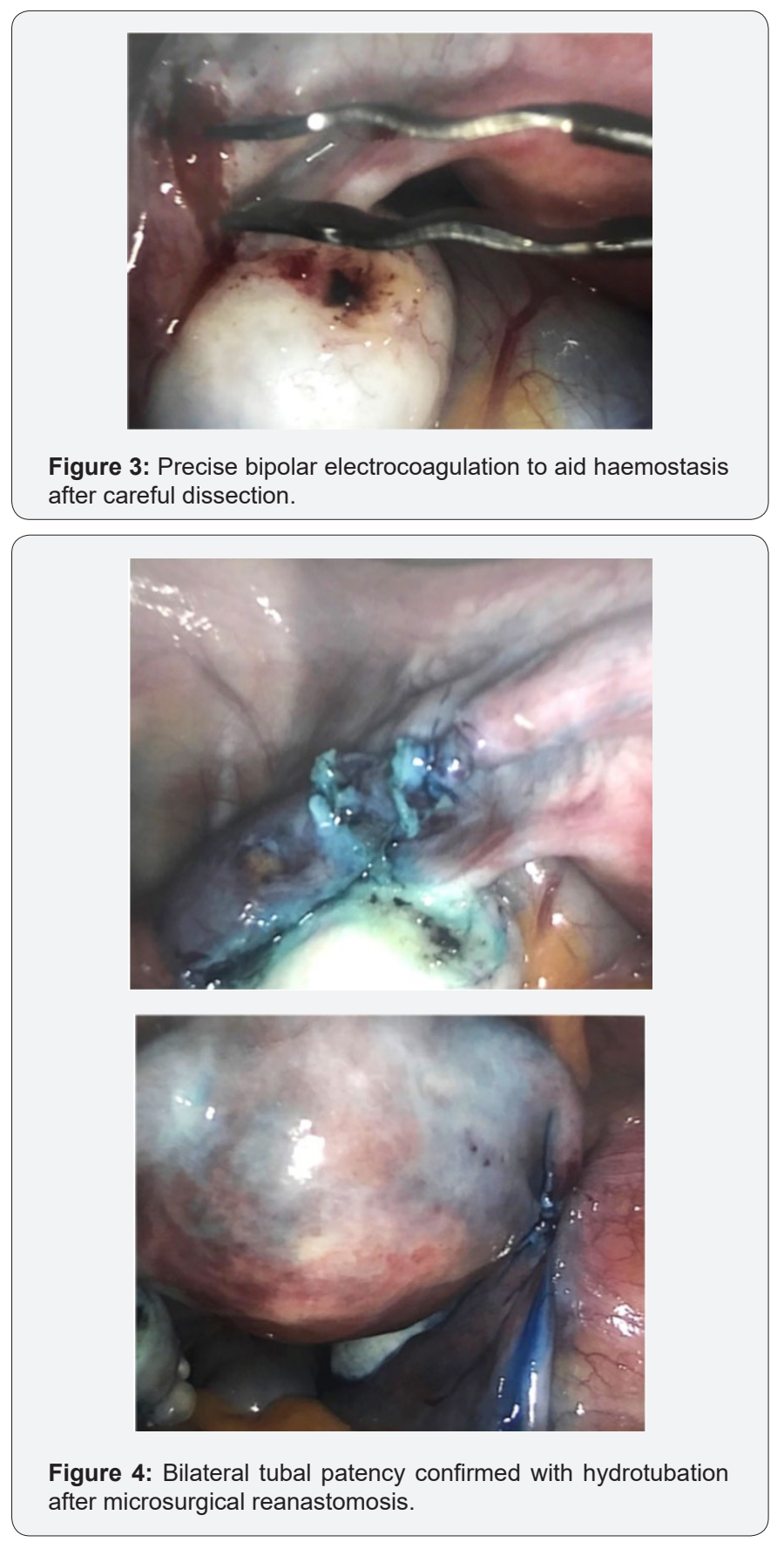

She was discharged uneventfully on the first post-operative day and conceived spontaneously during her next menstrual cycle. Her first dating ultrasound was performed at eight weeks of gestation, and she delivered at full term via a normal vaginal delivery without antenatal complications (Figures 4).

\section{Conclusion}

Based on our experience, reversal of tubal ligation has comparable subsequent intrauterine pregnancy rates to IVF treatment. Laparoscopic microsurgery offers the advantage of faster recovery with less postoperative discomfort, less complications and a smaller surgical scar. Tubal re-anastomosis also restores natural fertility, offering an alternative to artificial reproductive technology. Appropriate patient selection and counseling, together with operator training and experience contributes to favourable outcomes. More high quality studies should be encouraged to establish the objective comparative success rates in this developing surgical field.

\section{References}

1. Van Seeters JAH, Chua SJ, Mol BWJ, Koks CAM (2017) Tubal anastomosis after previous sterilization: a systematic review. Hum Reprod Update 23(3): 358-370.

2. Karaycalcin R, Ozcan S, Tokmak A, Gurlek B, Yenicesu O, et al. (2017) Pregnancy outcome of laparoscopic tubal reanastomosis: retrospective results from a single clinical centre. J Int Med Res 45(3): 1234-1242. 


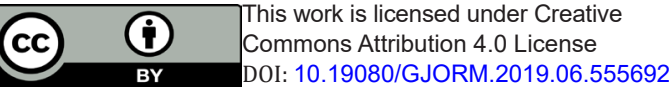

Your next submission with Juniper Publishers
will reach you the below assets
- Quality Editorial service
- Swift Peer Review
- Reprints availability
- E-prints Service
- Manuscript Podcast for convenient understanding
- Global attainment for your research
- Manuscript accessibility in different formats
( Pdf, E-pub, Full Text, Audio)
- Unceasing customer service
Track the below URL for one-step submission
https://juniperpublishers.com/online-submission.php

